\title{
Genotype-phenotype correlation analysis of MYO15A variants in autosomal recessive non-syndromic hearing loss
}

Jing Zhang ${ }^{1,2}$, Jing Guan ${ }^{1 *}$, Hongyang Wang ${ }^{1}$, Linwei Yin ${ }^{3}$, Dayong Wang ${ }^{1}$, Lidong Zhao ${ }^{1}$, Huifang Zhou ${ }^{2}$ and Qiuju Wang ${ }^{1 *}$ (D)

\begin{abstract}
Background: MYO15A variants are responsible for human non-syndromic autosomal recessive deafness (DFNB3). The majority of MYO15A variants are associated with a congenital severe-to-profound hearing loss phenotype, except for MYO15A variants in exon 2, which cause a milder auditory phenotype, suggesting a genotype-phenotype correlation of MYO15A. However, MYO15A variants not in exon 2 related to a milder phenotype have also been reported, indicating that the genotype-phenotype correlation of MYO15A is complicated. This study aimed to provide more cases of MYO15A variation with diverse phenotypes to analyse this complex correlation.

Methods: Fifteen Chinese autosomal recessive non-syndromic hearing loss (ARNSHL) individuals with MYO15A variants ( 8 males and 7 females) from 14 unrelated families, identified by targeted gene capture of 127 known candidate deafness genes, were recruited. Additionally, we conducted a review of the literature to further analyses all reported MYO15A genotype-phenotype relationships worldwide.

Results: We identified 16 novel variants and 12 reported pathogenic MYO15A variants in 15 patients, two of which presented with a milder phenotype. Interestingly, one of these cases carried two reported pathogenic variants in exon 2, while the other carried two novel variants not in exon 2. Based on our literature review, MYO15A genotypephenotype correlation analysis showed that almost all domains were reported to be correlated with a milder phenotype. However, variants in the N-terminal domain were more likely to cause a milder phenotype. Using next-generation sequencing (NGS), we also found that the number of known MYO15A variants with milder phenotypes in Southeast Asia has increased in recent years.

Conclusion: Our work extended the MYO15A variant spectrum, enriched our knowledge of auditory phenotypes, and tried to explore the genotype-phenotype correlation in different populations in order to investigate the cause of the complex MYO15A genotype-phenotype correlation.
\end{abstract}

Keywords: MYO15A, DFNB3, Phenotype, Deafness

\section{Background}

Sensorineural hearing loss (SNHL) is one of the most common sensory defects, affecting approximately 466 million people worldwide, 34 million of whom are children (http://www.who.int/). More than 50\% of congenital hearing impairment cases are attributable to genetic factors, with more than 100 syndromic and non-syndromic genes

\footnotetext{
* Correspondence: ggy3u@126.com; wqcr301@vip.sina.com

${ }^{1}$ Chinese PLA Institute of Otolaryngology, Chinese PLA General Hospital, Medical School of Chinese PLA, 28 Fuxing Road, Beijing 100853, China Full list of author information is available at the end of the article
}

known to date. Non-syndromic hearing loss (NSHL) is further categorized as autosomal dominant, autosomal recessive, X-linked, Y-linked or mitochondrial hearing loss. Autosomal recessive non-syndromic hearing loss (ARNSHL) accounts for up to $70 \%$ of NSHL. As of Jan 2019, more than 70 genes have been reported to be responsible for ARNSHL (http://hereditaryhearingloss.org/). Variants of GJB2, SLC26A4, MYO15A, OTOF, CDH23, $M Y O 7 A, T M C 1, H G F$ and $C I B$ are worldwide major contributors to ARNSHL [1], and myosin 15A (MYO15A, MIM: 602666) gene variants are the third or fourth most

C The Author(s). 2019 Open Access This article is distributed under the terms of the Creative Commons Attribution 4.0 International License (http://creativecommons.org/licenses/by/4.0/), which permits unrestricted use, distribution, and reproduction in any medium, provided you give appropriate credit to the original author(s) and the source, provide a link to the Creative Commons license, and indicate if changes were made. The Creative Commons Public Domain Dedication waiver (http://creativecommons.org/publicdomain/zero/1.0/) applies to the data made available in this article, unless otherwise stated. 
frequent causes of ARNSHL [2]. According to previous reports, the prevalence of $M Y O 15 A$ variants was 3 9.9\% (19/557) among Turkish ARNSHL patients, 5.7\% among Pakistani patients [1], 5.7\% among Iranian patients [3], $2.71 \%$ among Korean patients, $1.67 \%$ among Japanese patients (10/600) and 2.6\% among Chinese patients.

Encoded by $M Y O 15 A$, myosin XVa is a member of the unconventional myosin superfamily and plays an indispensable role in the graded elongation of stereocilia and actin organization in hair cells of the inner ear, which are essential for normal hearing function [4]. As a result, MYO15A variants are responsible for non-syndromic autosomal recessive deafness (DFNB3, OMIM 600316) in humans, whereas variants of homologous Myo15 genes lead to deafness and vestibular dysfunction in mice (shaker-2) [5-8].

Initially, the majority of $M Y O 15 A$ variants were documented in patients with severe to profound congenital sensorineural deafness phenotypes from consanguineous families in the Middle East and Southeast Asia. However, with the recent development of next-generation sequencing (NGS), the reported number of MYO15A variants has sharply increased in other countries and regions, such as East Asia and Europe. Contrary to previous reported severe auditory phenotypes, partial deafness with residual hearing at low frequencies was reported, always associated with pathologic variants in exon 2 affecting the encoding of the $\mathrm{N}$-terminal domain. Interestingly, recent studies have reported that some variants of MYO15A affecting the function of other domains, which were expected to bring about congenital severe to profound hearing loss, also were observed to result in various milder auditory phenotypes $[9,10]$.

In the present study, we reported 15 Chinese MYO15A variant cases from 14 unrelated ARNSHL families and identified 16 novel variants and 12 MYO15A variants in total by targeted gene capture and high-throughput sequencing. Additionally, we analysed all reported MYO15A genotype-phenotype relationships worldwide through a review of the literature. Our work extended the MYO15A variant spectrum, enriched our knowledge of auditory phenotypes, and tried to explore the genotype-phenotype correlation in different populations in order to investigate the cause of the complex MYO15A genotype-phenotype correlation.

\section{Methods}

\section{Participants}

A total of 15 Chinese ARNSHL individuals, ethnic Han, with MYO15A variants (8 males and 7 females) from 14 unrelated families, were recruited by the Department of Otolaryngology, Head and Neck Surgery of the Chinese PLA General Hospital. 127 known candidate deafness genes identifications were performed with targeted gene capture.

\section{Clinical evaluations}

For auditory assessment in all subjects, otoscopy, tympanometry, acoustic reflex thresholds, distortion product otoacoustic emission (DPOAE), and pure-tone audiometry following standard protocols were included. (Behavioural observation audiometry, visual reinforcement audiometry or play audiometry for young children.) Auditory brainstem response (ABR) and auditory steady state response (ASSR) were applied if the above subjective audiometric assessments could not be performed in infants. Family history and clinical questionnaires were available from all subjects or relatives.

The definition for severity of hearing impairment, according to pure-tone audiometry (PTA) of the better ear, was made based on the average hearing threshold level at four frequencies $(500,1000,2000$ and $4000 \mathrm{~Hz})$ of air conduction. 26-40 dB HL were considered to be mild hearing loss; 41-55 dB HL, moderate hearing loss; 56$70 \mathrm{~dB}$, moderately severe hearing loss; 71-90 dB HL, severe hearing loss; > $90 \mathrm{~dB} \mathrm{HL}$, profound hearing loss. The occurrence of hearing loss was categorized as prelingual ( $\leq 6$ years) or post-lingual ( $>6$ years).

\section{Targeted gene capture and high throughput sequencing} Blood DNA kit (Tiangen Biotech, Beijing, China) was used to extract Genomic DNA of all participants from peripheral blood. Targeted gene capture and highthroughput sequencing were then applied as reported thoroughly in a previous study [11]. Briefly, sequences of exons, splicing sites and flanking intron of 127 known deafness genes were captured simultaneously using a targeted genomic enrichment platform (Additional file 1: Table S1). Then the DNA library was established after performing sequencing of the target region in subjects. Targeted genes were amplified by PCR using universal primers, followed by sequencing of the PCR products through Illumina HiSeq 2000 (San Diego, California, USA). Burrows-Wheeler Aligner (BWA) (http://bio-bwa. sourceforge.net/) was applied to align reads to the NCBI37/hg19 assembly. SNPs, inserts and deletions were detected by Genome Analysis Toolkit (GATK) software and SAM tools (http://samtools.sourceforge.net/).

\section{Mutation analysis and control screening}

Potentially pathogenic variants including missense, nonsense, splice-site or frameshift variants with an allele frequency less than 0.01 were identified using the Genome Aggregation Database, the Exome Aggregation Consortium and 1000 Genomes databases. Simultaneous detection of point mutations, micro-indels, and duplications $(<20 \mathrm{bp})$ could be achieved. Pathogenicity of each 
missense variant was predicted using SIFT (http://sift. jcvi.org), PolyPhen-2 (http://genetics.bwh.harvard.edu/ pph2/) and Mutation Taster analyses (http://www.mutationtaster.org), while, GERP++ software (http://mendel. stanford.edu/sidowlab/downloads/gerp/index.html) and PhyloP (http: //compgen.bscb.cornell.edu/phast/) were performed to estimate the evolutionary conservation of the amino acid sequence. Genotyping for candidate pathogenic variants of all family members were underwent with Sanger sequencing. A PE9700 thermocycler (Applied Biosystems, Foster City, CA) was obtained for PCR, and then sequence analysis was carried out using an ABI 3730 Genetic Analyzer on affected cases and normal controls to determine if potential pathogenic mutations in the gene were co-segregating with the disease phenotype of these families. Further, aligning sequences were performed with the NCBI Reference Sequence and DNAStar software (DNASTAR, Madison, WI) to identify variants and polymorphisms. Finally, we selected 200 blood DNA samples from Chinese Han individuals with normal hearing as ethnically matched controls.

\section{Literature review of genotype-phenotype correlation of MYO15A variants}

Relevant researches were searched through PubMed using the MeSH terms "MYO15A" and "DFNB3" up until Jan 30, 2019. Inclusion criteria: 1) original articles and 2) reports of MYO15A variants with ARNSHL in humans.

\section{Results}

\section{Identification of MYO15A variants}

We identified a total of 28 potentially pathogenic variants of MYO15A in 15 NSHL patients from 14 families, only one of which was homozygous and 14 were compound heterozygotes (Additional file 2: Figure S1). Among all 28 MYO15A variants, 16 variants were novel: 9 missense variants (p.Arg1248Trp, p.Ala1556Thr, p.Ser1583Pro, p.Ala1608Glu, p.Leu1836Pro, p.Pro2160Leu, p.Asp2608 Asn, p.Arg2924His, p.Leu3501Glu), 3 splice site variants (c.4597-2A > G, c.6177 + 1G > T, c.7396-1G > A), 3 frameshift variants (p.Gln2571Hisfs*35, p.Asn2678fs, Leu2693Cysfs"45) and one nonsense variant (p.Arg1898*). Coincidentally, two families (family 1,607,486 and 707,757 ) in our study shared one identical novel variant, c.7396-1G > A. The remaining 12 variants were previously reported: p.Pro286Serfs*15 [12], p.Ser1176Valf*14 [13], p.Gly1418Arg [14], p.Ser1481Pro [15-17], c.4596 + 1G > A [18], c.5964+3G > A [19, 20], p.Arg1993Trp [21], p.Val2266Met [22], p.Arg2775His, p.Trp2931Glyfs"103, p.Phe3420del [20, 21, 23] and p.Ser3474Gly [24]. Co-segregation of these variations with ARNSHL in the families was confirmed using Sanger sequencing. In addition, the allele frequency in the ExAC, 1000 Genomes and gnomAD databases was less than 0.01. Almost all missense variants except p.Arg2924His were predicted to be pathogenic by SIFT, Mutation Taster and PolyPhen-2. These variants were absent in 200 normal Chinese controls (Additional file 3: Table S2). One particular concern was in samples 1,607,545 (p.Pro286Serfs"15, p.Ser1176Valfs"14 and p.Asp2608Asn) and 18,023,134 (c.4597-2A > G, p.Leu2693Cysfs"45 and p.Ser3474Gly), each of which had three MYO15A variants (Table 1). In sample $1,607,545$, although p.Pro286Serfs*15 and p.Ser1176Valfs"14 have been reported as pathogenic MYO15A variants $[12,13]$, the novel variant p.Asp2608Asn cannot yet be been ruled out because of its extremely low minor allele frequency (MAF) in multiple databases and because of pathogenicity prediction results from missense variant prediction software. Additionally, determining the pathogenicity of the Ser3474Gly variant is quite problematic due to the finding of two homozygotes with an unknown phenotype in the ExAC database and because this variant has been reported as not pathogenic in a Korean DFNB3 family [24]. Another particular concern is c.5964+3G >A, which has been reported three times in the Chinese population and therefore appears to be a common MYO15A variant in Chinese NSHL patients $[19,20]$.

\section{Clinical findings}

Among the 15 individuals with $M Y O 15 A$ variants, patients $1,607,486-1$ and $1,607,486-2$ are siblings from the same family, while the remaining 13 individuals are from different families. The details of the clinical findings, including gender, age of test, age of onset, and hearing impairment phenotype, are summarized in Table 1 . We further analysed the auditory phenotype in these patients with $M Y O 15 A$ gene variants. We found that there were at least two distinct auditory phenotypes that could be classified as a relatively severe and a less severe phenotype, based on diverse hearing impairment characteristics. The majority of these 15 cases presented with a severe auditory phenotype including bilateral, symmetrical and congenital severe or profound hearing loss at all frequencies; however, patients 1,507,382 and $1,607,545$ presented with a milder phenotype. Patient $1,507,382$, a 9 -year-old boy, was first diagnosed with sensorineural hearing loss at 5 years of age. However, this boy's enunciation was unclear; therefore, we speculated that this boy had pre-lingual hearing loss. Audiograms for this boy displayed bilateral, symmetrical severe sensorineural HL mainly affecting high frequencies, with residual hearing at low frequencies. Furthermore, we annually performed follow-up auditory assessments for this boy from 6 to 9 years of age. The result showed that pure tone thresholds had increased to approximately 


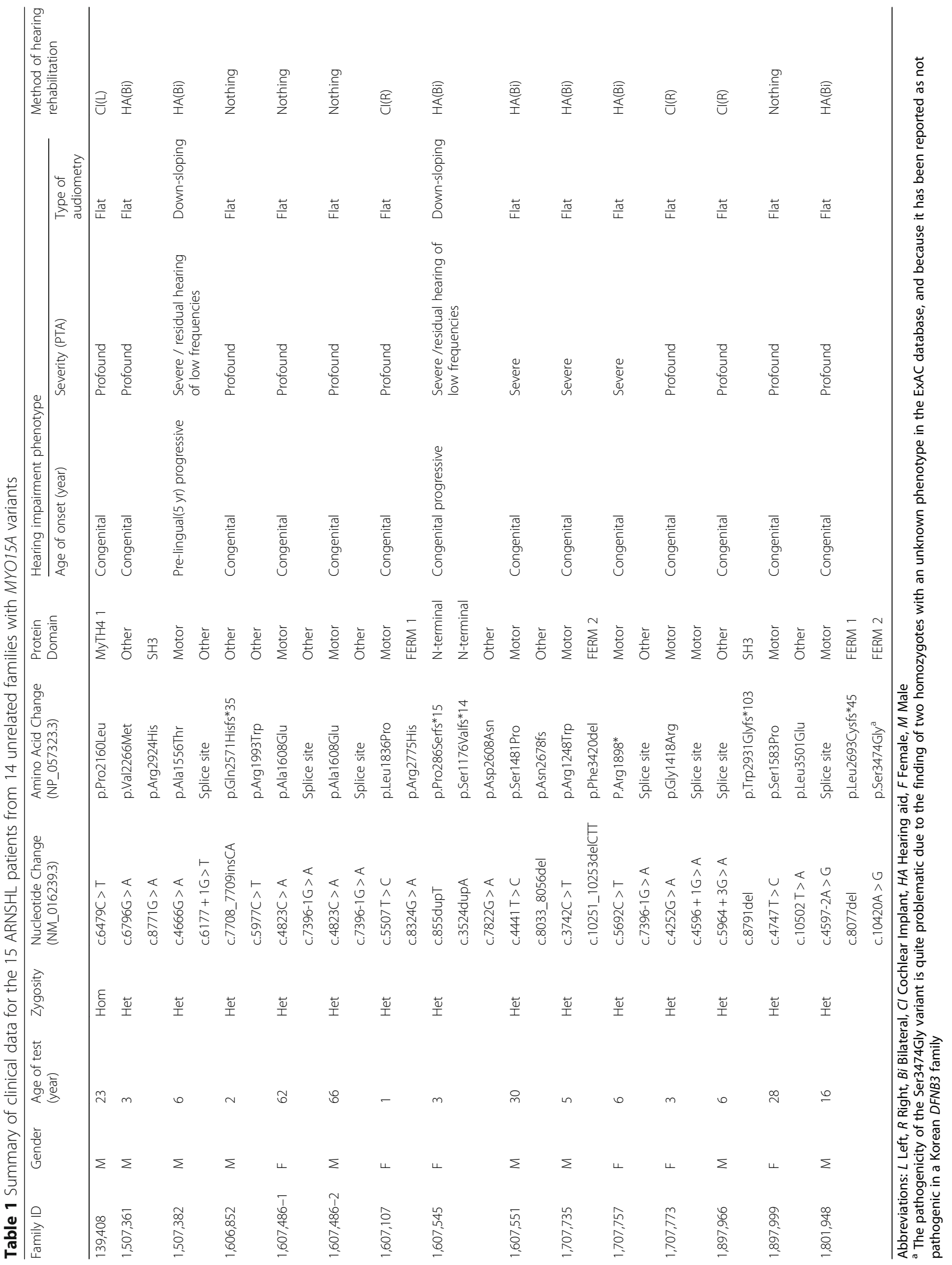


$30-40 \mathrm{~dB}$ HL at $0.25 \mathrm{kHz}-0.5 \mathrm{kHz}$ and $10-20 \mathrm{~dB} \mathrm{HL}$ at $1 \mathrm{kHz}-8 \mathrm{kHz}$ in the bilateral ears (Fig. 1a). Patient $1,607,545$ is another case with a milder phenotype who was found with congenital hearing impairment through newborn hearing screening using otoacoustic emission (OAE). As for the previous patient, we performed three follow-up assessments for this girl at the ages of 3,4 and 6 years, using visual reinforcement audiometry or play audiometry. Audiograms showed bilateral progressive severe to profound sensorineural $\mathrm{HL}$, mainly affecting high frequencies, with moderate residual hearing at low frequencies (Fig. 1b).

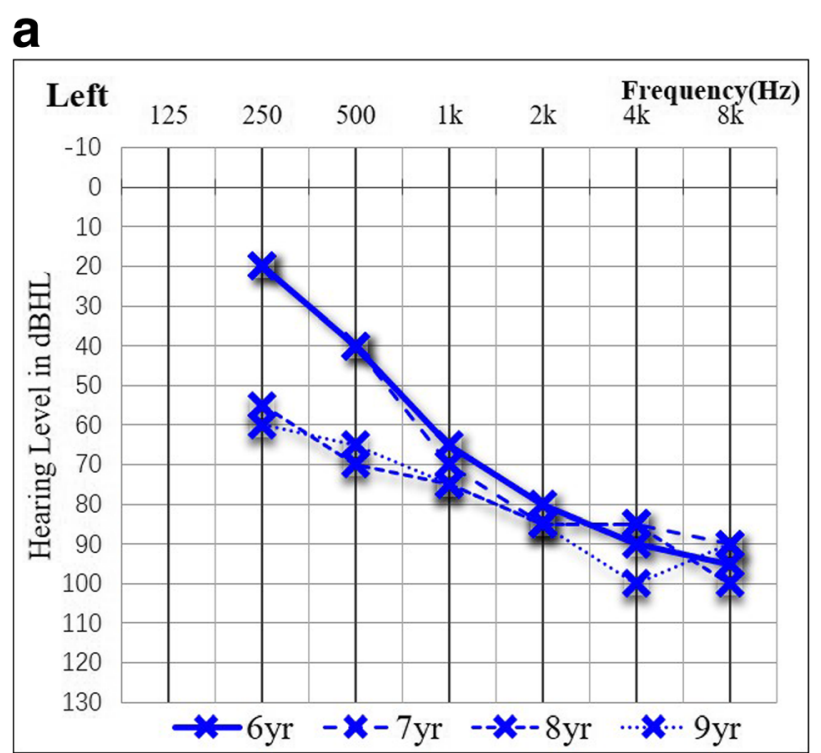

Patient 1507382-Left ear

b

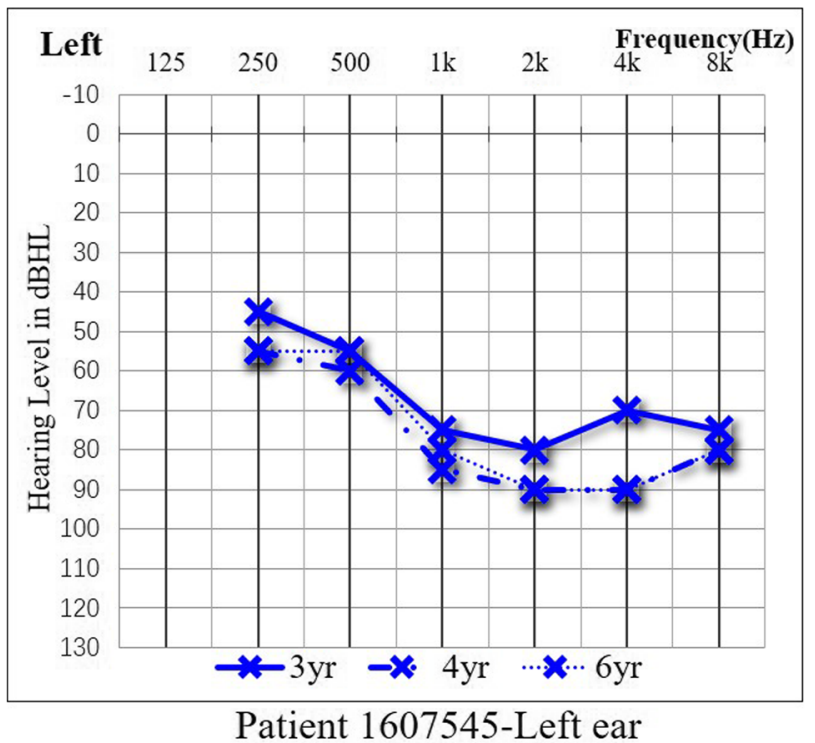

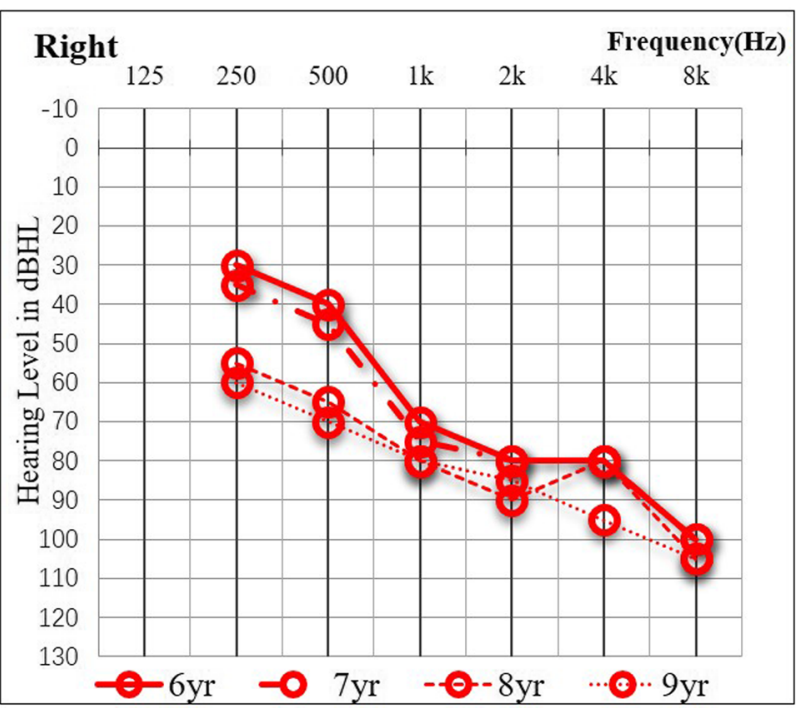

Patient 1507382-Right ear

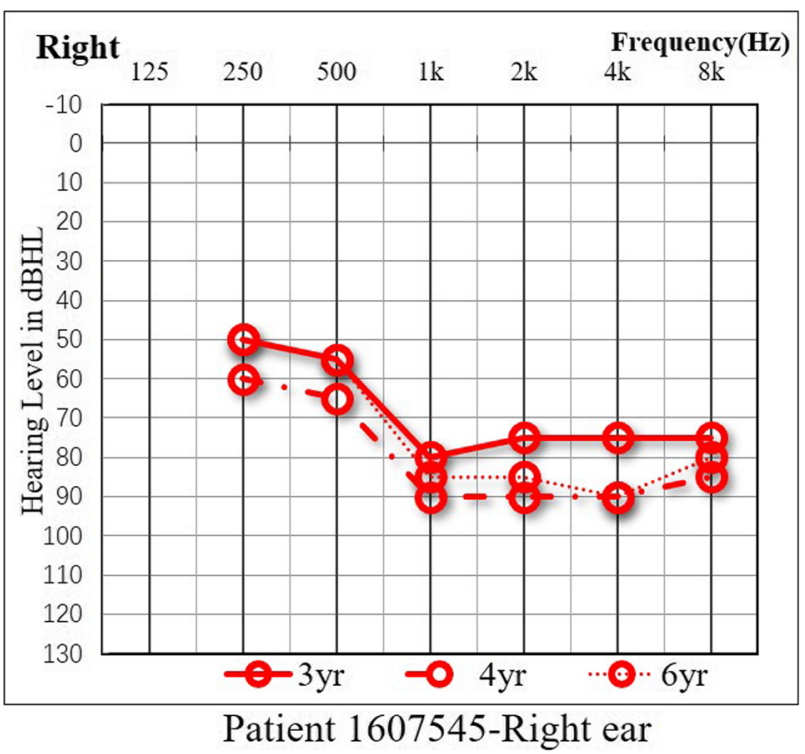

Fig. 1 Audiograms of case 1,507,382 and 1,607,545. a The solid line represents the auditory thresholds measured when case 1,507,382 was 6 years old. The audiogram shows bilateral symmetrical severe sensorineural HL mainly affecting high frequencies, with residual hearing at low frequencies. Dashed lines indicate the results of auditory follow-up at seven, eight and nine years old, respectively. The pure tone threshold of this child increased by approximately $30-40 \mathrm{~dB} \mathrm{HL}$ at $0.25 \mathrm{kHz}-0.5 \mathrm{kHz}$ and $10-20 \mathrm{~dB} \mathrm{HL}$ at $1 \mathrm{kHz}-8 \mathrm{kHz}$ in the bilateral ears. b The solid line represents the auditory thresholds measured when case 1,607,545 was three years old, and the dashed lines display auditory thresholds when the child was four and six years old, respectively. The audiograms of the case 1,607,545 show bilateral residual hearing at low frequencies with progressive hearing loss at all frequencies. $\mathrm{HL}$, hearing loss; $\mathrm{dB}$, decibels; $\mathrm{Hz}$, Hertz 


\section{Literature review of the genotype-phenotype correlation} of MYO15A variants

Finally, a total of $249 \mathrm{MYO} 15 \mathrm{~A}$ variants associated with $D F N B 3$ were reported in the literature, including 38 splice site variants (Fig. 2a and b) [1-3, 5, 9, 10, 12-69]. After filtering out the 65 variants without reported hearing loss phenotypes, we endeavoured to explore the relationship between the genotypes and auditory phenotypes in the remaining 184 variants of $M Y O 15 A$. To our surprise, almost all domains had been reported to be correlated with a milder phenotype; however, variants encoding the $\mathrm{N}$-terminal domain were more likely to cause a milder phenotype (Fig. 2c). Since 2007, when the first MYO15A variant case with a milder hearing impairment phenotype from Pakistan was published, advances in high-throughput techniques have led to a fast-growing number of reported MYO15A variants with a milder auditory phenotype in additional countries, especially in Southeast Asia (Fig. 3). Table 2 shows details of all reported MYO15A variant cases associated with milder phenotypes.

We further summarized the genotype-phenotype correlation of the MYO15A variant in different populations (Fig. 4). In our review, the reported number of $M Y O 15 A$ variants in individuals from Middle East, Southeast Asia, South Asia, Europe, South America and North America was 99, 92, 42, 23, 7 and 2, respectively, and the reported number of $M Y O 15 A$ variants from Middle Eastern was largest. However, the number of known MYO15A variants in Southeast Asia has increased in recent years. Moreover, based on our review, we found a notable genetic characteristic that occurs in different populations. In the Middle East and South Asia, most MYO15A variants were homozygous variants, probably resulting from the custom of consanguineous marriage in these areas. However, more compound heterozygous variants have been identified in Southeast Asia and Europe in recent years (Fig. 5).

\section{Discussion}

In 1995, the DFNB3 locus was first mapped to chromosome $17 \mathrm{p}-17 \mathrm{q} 12$ by linkage analysis in two large multi-generational non-consanguineous families from a remote Indonesian village, Bengkala, where $2.2 \%$ of the population $(47 / 2185)$ had severe-to-profound hearing loss. The locus was subsequently further refined to chromosome 17p11.2 [70, 71]. Since 1998, when three homozygous variants of MYO15A were initially identified in three multigenerational ARNSHL families from Indonesia and India [5], more than 200 variants have been reported to date. Our results expanded the spectrum of sequence variants in the MYO15A gene. In the present study, we identified 16 novel possible pathogenic variants, including one nonsense variant, two \pm 1 or 2 splice site variants, three frameshift variants with evidence of pathogenicity and 9 missense variants (p.Arg1248Trp, Ala1556Thr, p.Ser1583Pro, p.Ala1608Glu, p.Leu1836Pro, p.Pro2160Leu, p.Asp2608Asn, Arg2924His, p.Leu3501Glu).

The MYO15A gene contains 67 exons and encodes several alternatively spliced transcripts, and the longest mRNA transcript contains 3530 amino acids. It includes a long $\mathrm{N}$-terminal extension encoded by giant exon 2 , an ATPase motor domain, two light chain binding IQ motifs, and a tail region containing two myosin-tail homology 4 (MyTH4) domains, two band 4.1 superfamily (ezrin, radixin and moesin) (FERM), a Src-homology-3 (SH3) domain and a C terminal class I PDZ-ligand domain. Additionally, based on the presence or lack of giant exon 2, there are two alternatively spliced transcripts, isoform classes II and I. Myosin XVa is a member of the unconventional myosin superfamily, which is indispensable in the graded elongation of stereocilia of cochlear and vestibular hair cells. Whirlin is a scaffolding protein that is essential for maintaining normal human hearing (DFNB31, OMIM \#607084) and sight (USH2D, OMIM \#611383). EPS8 is an actin capping protein and is similarly essential for human hearing (DFNB102, OMIM \#615974). Myosin XVa can transport whirlin and Eps8 to the tip of stereocilia and interacts with them to form a stereocilia tip complex, which can facilitate the extremely important transformation of microvilli into mature stereocilia [72]. Shaker-2 (Myo15sh2) mice exhibit profound hearing loss and abnormal vestibular function caused by short stereocilia and by losing the normal staircase structure of stereocilia in hair cells [7, 8].

In our literature review, the number of $M Y O 15 A$ variants affecting the motor domain is the largest of all domains (Fig. 2c). The motor domain consists of ATP- and actin-binding sites, which can generate force and move actin filaments; therefore, it is not surprising that motor domain dysfunction affected by the MYO15A variant will lead to shorter stereocilia with an ectopic staircase structure of stereocilia associated with a severe deafness phenotype [73]. Earlier studies showed that the motor and tail regions of myosin XVa were critical for normal auditory structure and function, whereas the exact biological function of the large $\mathrm{N}$-terminal extension initially remained obscure [73]. However, recent study demonstrated that the $133-\mathrm{kDa}$-terminal domain enables myosin 15 to maintain mechanotransducing stereocilia and is essential for hearing [74]. In 2007, two mutant alleles encoding the $\mathrm{N}$-terminal domain were identified that provided evidence that the class I isoform of myosin XVa with an $\mathrm{N}$-terminal extension is essential for normal hearing in humans [22]. More particularly, compared with the previous phenotype involving profound hearing loss at all frequencies, a milder phenotype 


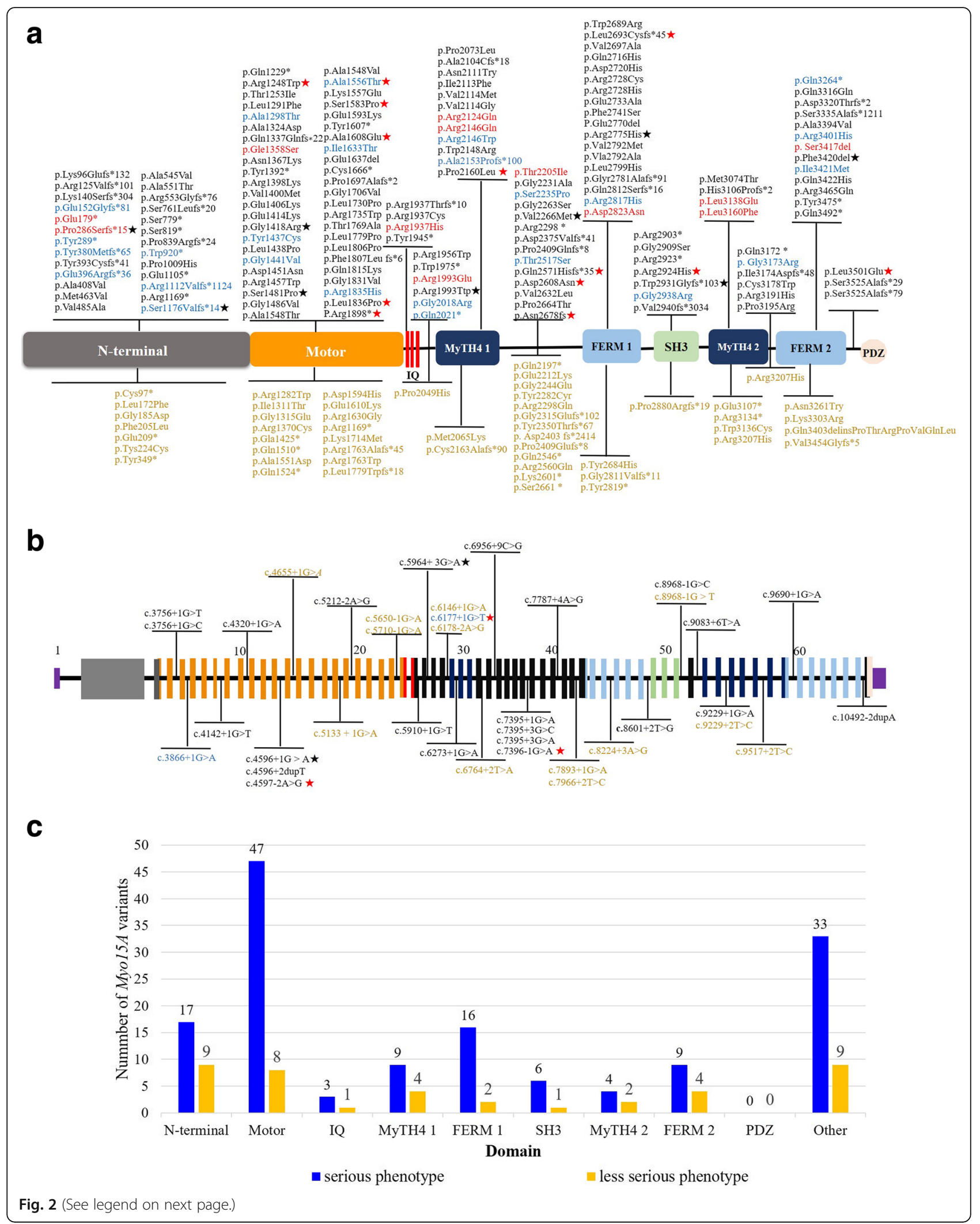


(See figure on previous page.)

Fig. 2 Overview of known MYO15A variants and related hearing phenotypes. The blue words indicate variants associated with milder auditory phenotypes, the red words indicate variants associated with reported both severe and milder phenotypes. In addition, variants without reported hearing loss phenotypes are expressed in brown words. Sixteen red stars indicate novel variants of MYO15A in this study, and eleven black stars show previously reported variants of MYO15A in this study. a Except for splice site variants of MYO15A, 159 MYO15A variants with reported hearing phenotypes were noted above the schematic diagram, 52 variants without reported hearing phenotypes were listed under it. $\mathbf{b}$ Thirty-eight splice site variants of MYO15A were indicated on the border between the exons flanking and affected introns. The pathogenicity of p.Ser3474Gly is ambiguous, so it is not listed here. $\mathbf{c}$ The number of identified MYO15A variants with two different auditory phenotypes in every affected domain is displayed

with residual hearing at low frequencies $(250 \mathrm{~Hz}, 500$ $\mathrm{Hz}$ ) was shown for the first time. In addition, abnormally short stereocilia could be restored to a wild type-like staircase architecture by simply transfecting myosin XVa Isoform II in shaker-2 mice. Therefore, it was hypothesized that a variant in the $\mathrm{N}$-terminal extension domain might be associated with functional problems or minor structural defects in the staircase architecture of hair cell stereocilia [22]. Further, the results from the later mouse model experiments suggested that the pathogenic mechanisms of the two isoforms were different. Isoform II with no N-terminal domain can transport whirlin and EPS8 to the tips of hair cell stereocilia and drive elongation of the core actin cytoskeleton. Alternatively, Isoform I, with an $\mathrm{N}$-terminal domain, is responsible for stabilizing the actin cytoskeleton and preventing the disassembly of mature mechano-transduction sites [2] . This finding suggests that there may be a genotype-phenotype correlation. Variants in giant exon 2, which may seldom result in drastic changes in the protein structure and function of the inner ear, may be involved in a variety of milder hearing loss phenotypes, such as residual hearing at low frequencies,

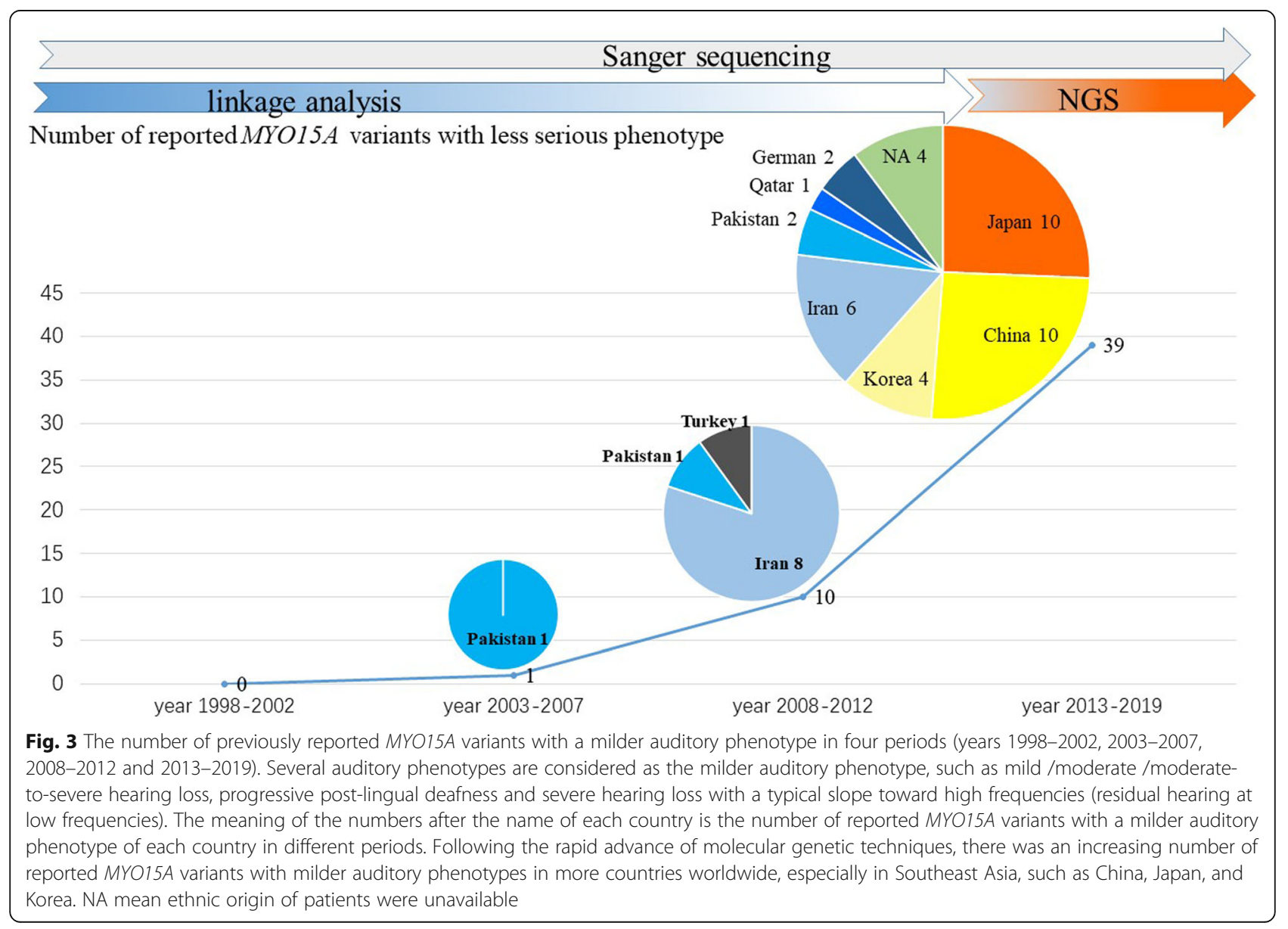




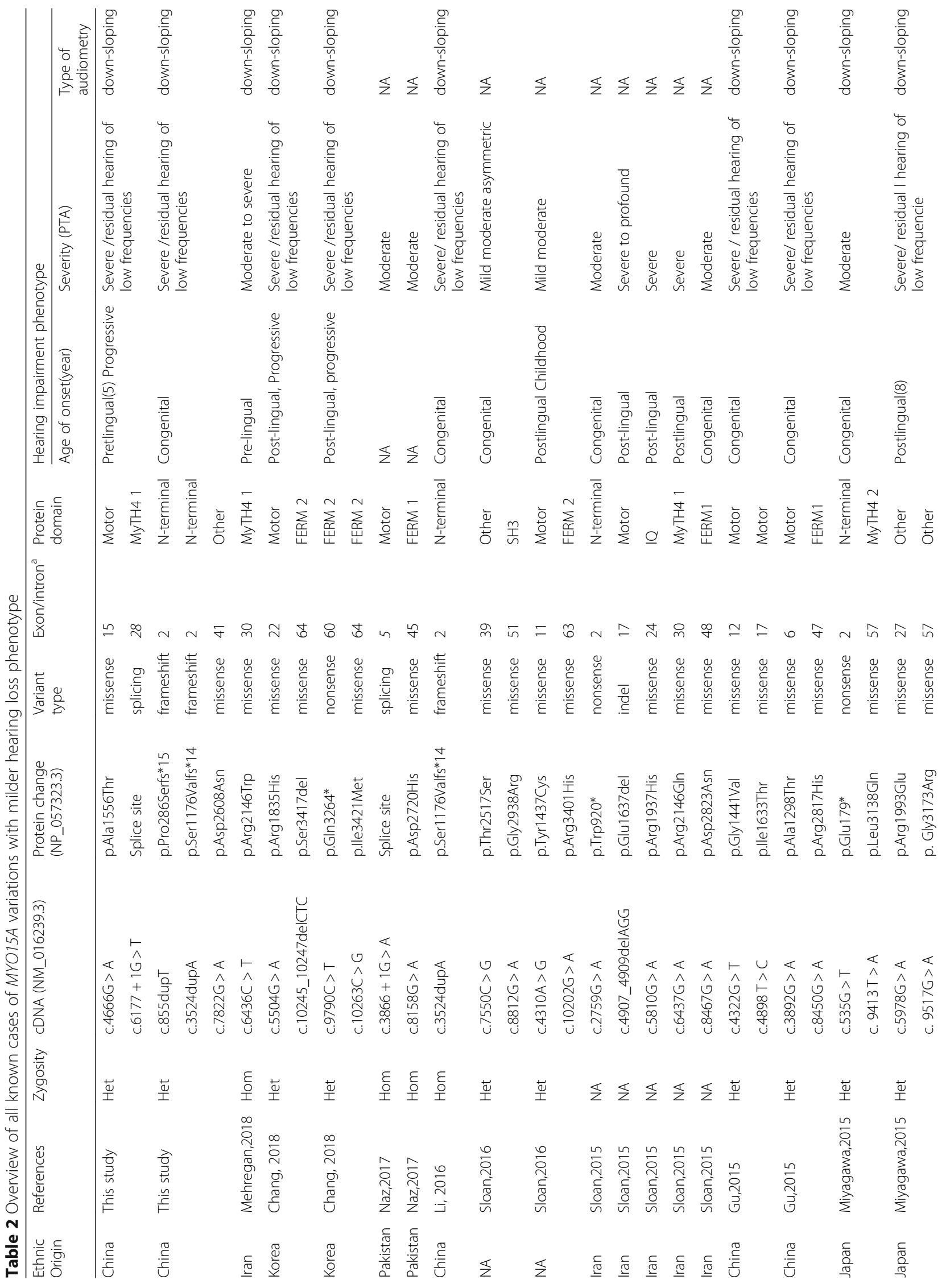




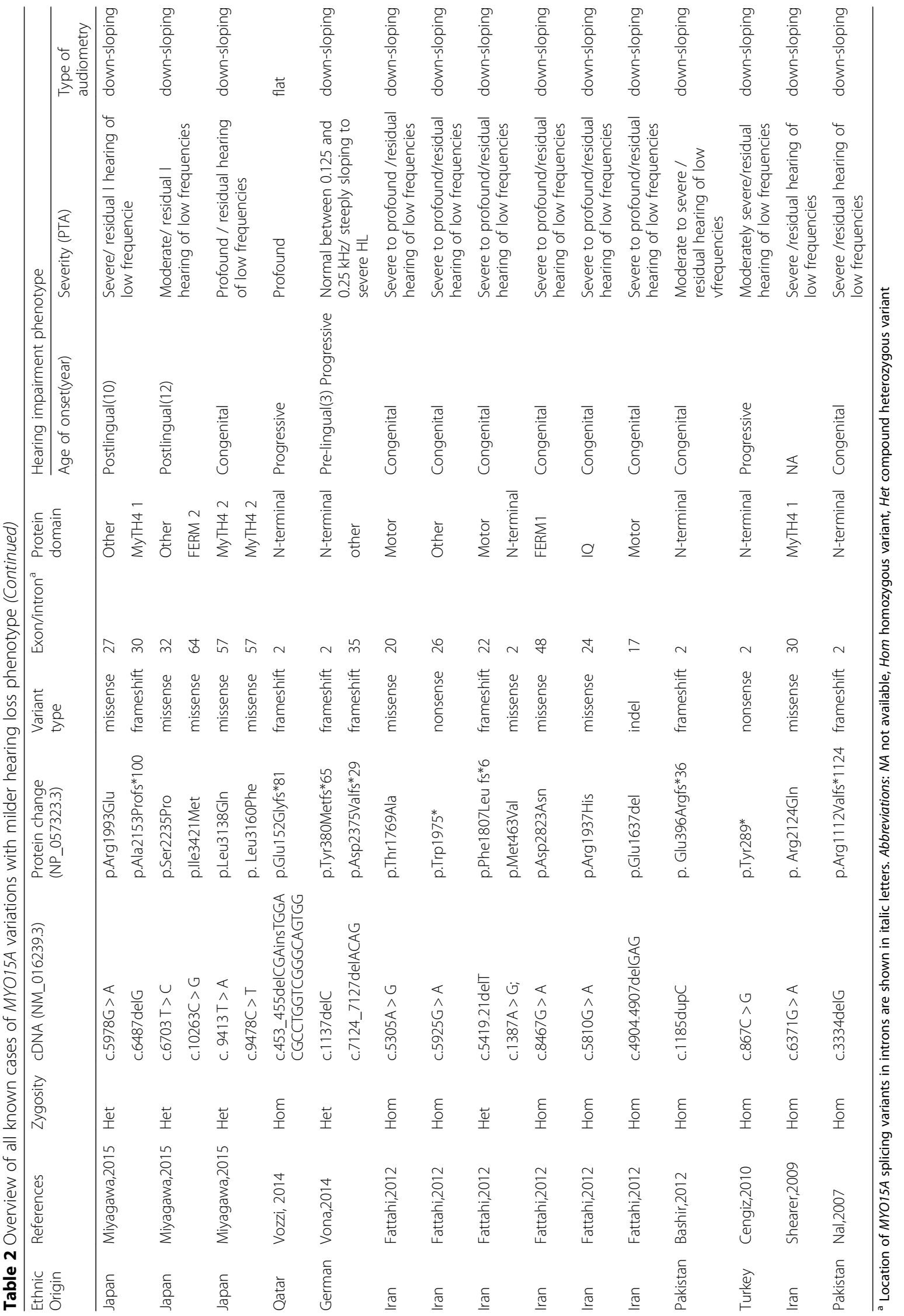




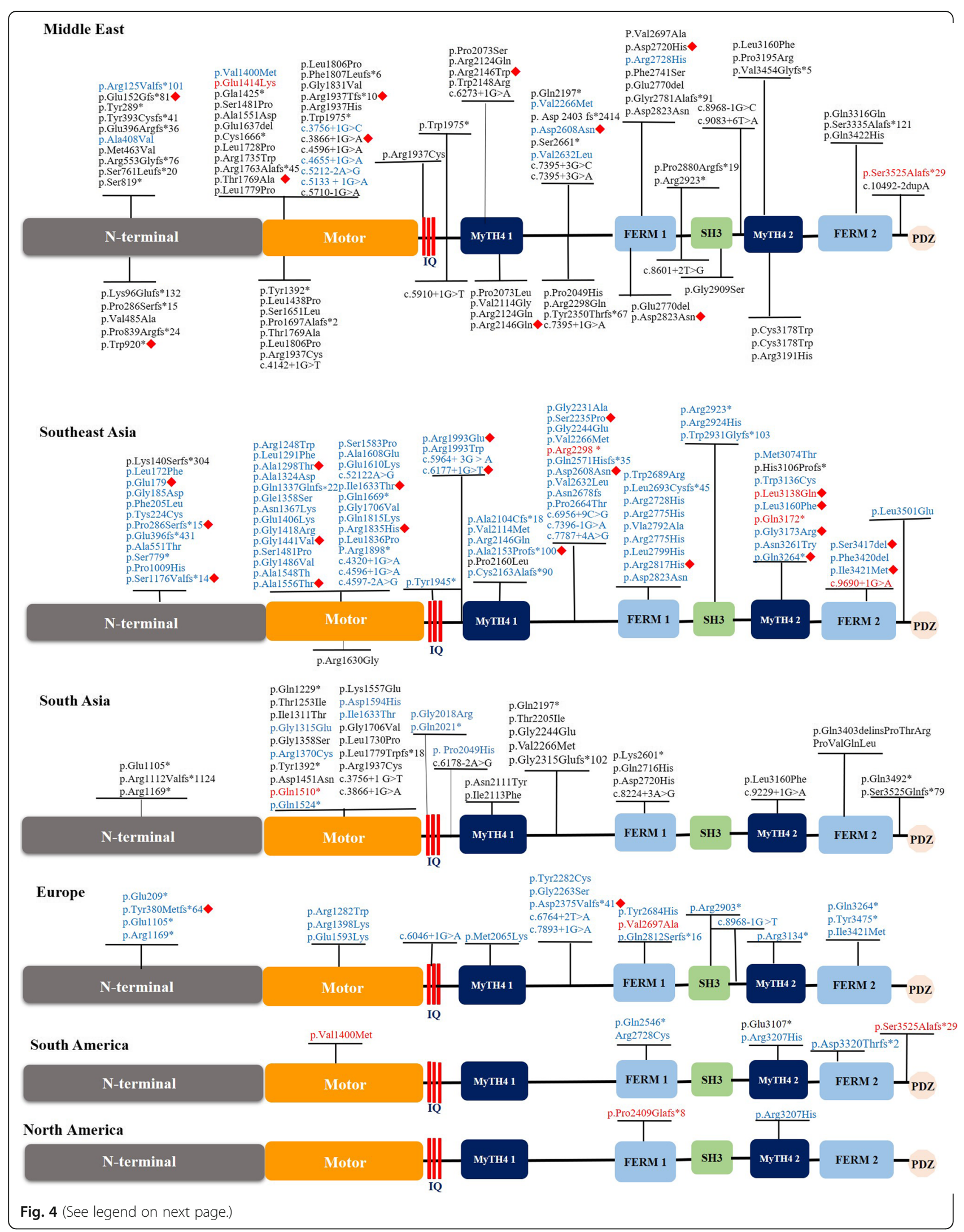


(See figure on previous page.)

Fig. 4 The spectrum of MYO15A variants in different populations. The black words indicate homozygous variants, the blue words indicate compound heterozygous variants and the red words represent MYO15A variants that were reported with both compound heterozygous and homozygous variants. In all populations, MYO15A variants with known zygosity types were noted above the schematic diagram, and variants with unknown zygosity types were noted below it. Red diamond-shaped signs in all populations designate MYO15A variants with milder auditory phenotypes

moderate-to-severe hearing loss and progressive post-lingual deafness. In our study, we reported one case (1607545) with two compound heterozygous variants (p.Pro286Serfs"15, p.Ser1176Valfs"14) in 2 exons encoding the $\mathrm{N}$-terminal domain who showed residual hearing at low frequencies. It is rather remarkable that this homozygous MYO15A variant (p.Ser1176Valfs"14) had recently been identified in a non-consanguineous Chinese family. The audiograms of two affected siblings also showed moderate residual hearing at identical low frequencies, which seems to provide additional evidence of an association between the mutant allele p.Ser1176Valfs"14 and a less severe auditory phenotype, especially in Chinese families [13]. In addition, our literature review illustrated that variants in the $\mathrm{N}$-terminal domain were more frequently related to less sever hearing impairment than variants in the other domains.

A genotype-phenotype correlation of MYO15A variants should predict hearing loss tendency according to affected domain, which will inform the choice of optimal hearing rehabilitation methods for individuals [43]. For instance, on the basis of this hypothetical genotype-phenotype correlation, cases with variants affecting the $\mathrm{N}$-terminal extension seem to need cochlear implantation with low frequency hearing retention or hearing aids due to their milder hearing loss. However, upon review of the relevant literature, we found that the genotype-phenotype correlation of MYO15A was much more complicated. First, recent studies showed that some pathologic variants affecting domains (motor, IQ, MyTH4 1, FERM 1, SH3, MyTH4 2, FERM 2) that would have been expected to cause a severe hearing phenotype, actually resulted in a milder auditory phenotype. The above relationship was further confirmed by our finding that case (1507382) showed residual low-frequency hearing and compound heterozygosity for MYO15A (c.4666G > A, c.6177 + 1G > $\mathrm{T}$ ), affecting the motor and MyTH4 1 domains. Conversely, some variants associated with dysfunction of the $\mathrm{N}$-terminal domain cause congenital severe to profound hearing loss instead of a milder phenotype. In addition, we reviewed 12 MYO15A variants associated with both severe and milder phenotypes (Table 3). We found that affected members of the same family expressed different auditory phenotypes, even though they carried the same MYO15A variants $[17,60]$. For instance, Cengiz et al. [17] reported a Turkey ARNSHL family carried a homozygous MYO15A

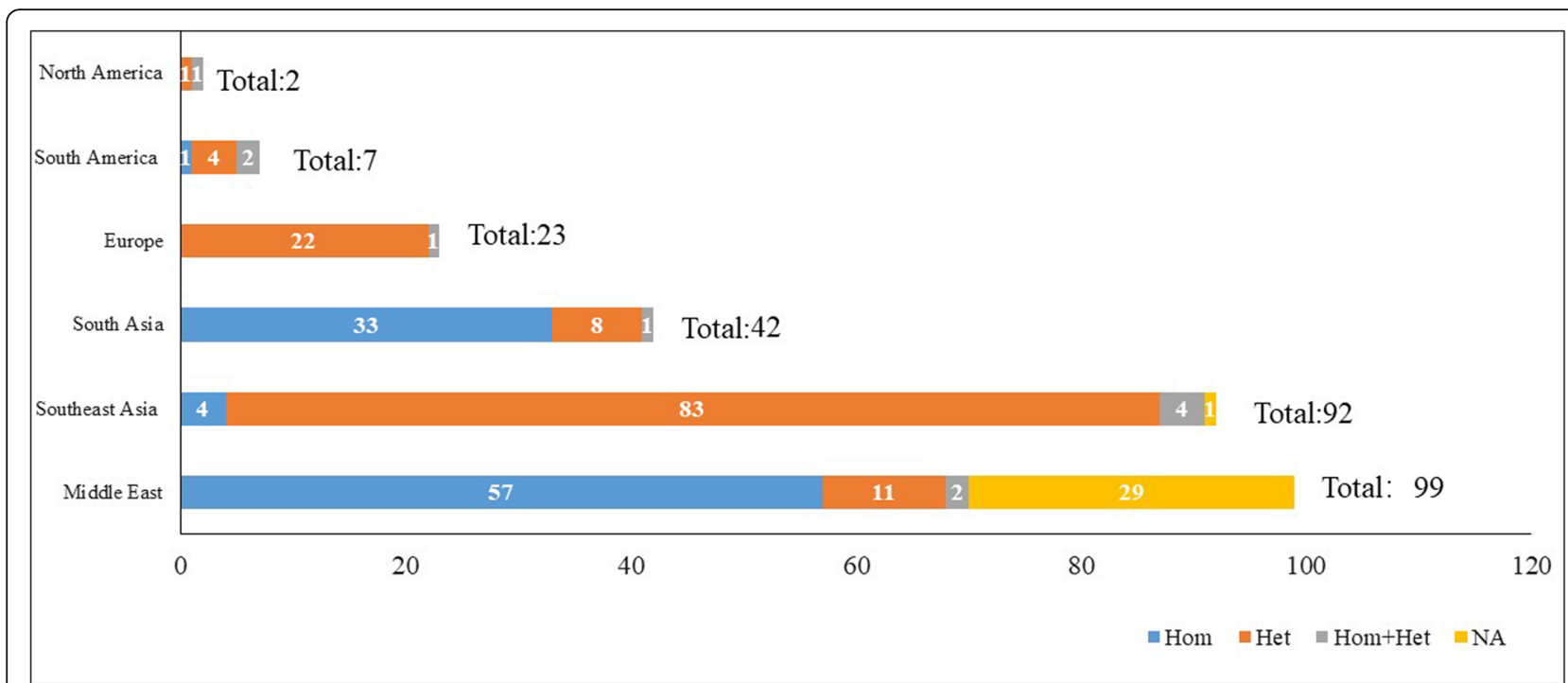

Fig. 5 The number of identified variants in different populations. The rank (from high to low) of reported number of MYO15A variants in different populations in the Middle East, Southeast Asia, South Asia, Europe, South America, and North America. This illustrates that in the Middle East and South Asia, most MYO15A variants were homozygous variants. On the other hand, more compound heterozygous variants were identified in Southeast Asia and Europe 
Table 3 Reported variants of MYO15A related to both a severe hearing loss phenotype and a milder hearing loss phenotype

\begin{tabular}{|c|c|c|c|c|c|c|c|c|}
\hline \multirow[t]{2}{*}{ cDNA (NM_016239.3) } & \multirow{2}{*}{$\begin{array}{l}\text { Protein chang } \\
\text { (NP_057323d.3) }\end{array}$} & \multirow{2}{*}{$\begin{array}{l}\text { Exon/ } \\
\text { Intron }\end{array}$} & \multirow[t]{2}{*}{ Proteindomain } & \multirow[t]{2}{*}{ Zygosity } & \multicolumn{2}{|c|}{ Hearing impairment phenotype } & \multirow{2}{*}{$\begin{array}{l}\text { Ethnic } \\
\text { Origin }\end{array}$} & \multirow[t]{2}{*}{ References } \\
\hline & & & & & $\begin{array}{l}\text { Age of } \\
\text { onset(year) }\end{array}$ & Severity & & \\
\hline \multirow[t]{2}{*}{$c .535 G>T$} & p.Glu179* & 2 & $\mathrm{~N}$-terminal & Het & Congenital & Profound & Korea & ParK,2014 \\
\hline & & & & Het & Congenital & Moderate & Japan & Miyagawa,2015 \\
\hline \multirow[t]{2}{*}{ c.855dupT } & p.Pro286Serfs*15 & 2 & $\mathrm{~N}$-terminal & Het & $\begin{array}{l}\text { Pre-lingual } \\
\text { progressive }\end{array}$ & $\begin{array}{l}\text { Severe /Residual low } \\
\text { frequencies hearing }\end{array}$ & China & this study \\
\hline & & & & Hom & Congenital & Severe to profound & Iran & Sloan,2015 \\
\hline \multirow[t]{2}{*}{$c .4072 \mathrm{G}>\mathrm{A}$} & p.Gle1358Ser & 9 & Motor & Het & Post-lingual & Mild & Japan & Miyagawa,2015 \\
\hline & & & & Hom & Congenital & Profound & $\begin{array}{l}\text { Pakistan/ } \\
\text { India }\end{array}$ & Friedman,2002 \\
\hline \multirow[t]{3}{*}{ c.5810G > A } & p.Arg1937His & 24 & IQ & NA & Post-lingual & Severe & Iran & Sloan,2015 \\
\hline & & & & Het & Childhood & Severe to profound & Iran & Sloan,2016 \\
\hline & & & & Hom & Congenital & Severe to profound & Iran & Fattahi,2012 \\
\hline \multirow[t]{3}{*}{ c.5978C > T } & p.Arg1993Gln & 27 & Other & Het & Post-lingual (8) & Severe & Japan & Miyagawa,2015 \\
\hline & & & & Het & $\begin{array}{l}\text { Post-lingual } \\
\text { (10) }\end{array}$ & Severe & Japan & Miyagawa,2015 \\
\hline & & & & Het & Pre-lingual & Severe & Japan & Miyagawa,2013 \\
\hline \multirow[t]{3}{*}{ c.6371G > A } & p.Arg2124Gln & 30 & MyTH4 1 & NA & Congenital & Severe to profound & Iran & Sloan,2016 \\
\hline & & & & Hom & NA & Severe to profound, & Iran & Shearer,2009 \\
\hline & & & & Hom & NA & $\begin{array}{l}\text { Residual low frequencies } \\
\text { hearing }\end{array}$ & Iran & Shearer,2009 \\
\hline \multirow[t]{2}{*}{ c.6437G > A } & p.Arg2146Gln & 30 & MyTH4 1 & NA & Post-lingual & Severe & Iran & Sloan,2015 \\
\hline & & & & Het & Congenital & Severe to profound & Korea & Woo,2013 \\
\hline \multirow[t]{2}{*}{ c.6614C > T } & p.Thr2205lle & 31 & Other & Het & Congenital & Severe to profound & Iran & Sloan,2016 \\
\hline & & & & Hom & Congenital & Severe to profound & Pakistan & $\mathrm{Nal}, 2007$ \\
\hline \multirow[t]{3}{*}{$c .8467 G>A$} & p.Asp2823Asn & 48 & FERM 1 & NA & Congenital & Moderate & Iran & Sloan,2015 \\
\hline & & & & Homo & Congenital & Profound & Israel & Brownstein,2014 \\
\hline & & & & Homo & Congenital & Severe to profound & Iran & Fattahi,2012 \\
\hline \multirow[t]{3}{*}{ c. $9413 \mathrm{~T}>\mathrm{A}$} & p.Leu3138Gln & 57 & MyTH4 2 & Het & Congenital & Moderate & Japan & Miyagawa,2015 \\
\hline & & & & Homo & Congenital & Profound & Japan & Miyagawa,2015 \\
\hline & & & & Het & Congenital & $\begin{array}{l}\text { Profound/residual low } \\
\text { frequencies hearing }\end{array}$ & Japan & Miyagawa,2015 \\
\hline \multirow[t]{6}{*}{ c. $9478 \mathrm{C}>\mathrm{T}$} & p.Leu3160Phe & 57 & MyTH4 2 & Het & Childhood & Profound & Iran & Sloan,2016 \\
\hline & & & & Het & Congenital & Profound & Japan & Miyagawa,2015 \\
\hline & & & & Het & Congenital & $\begin{array}{l}\text { Profound/ residual low } \\
\text { frequencies hearing }\end{array}$ & Japan & Miyagawa,2015 \\
\hline & & & & Het & $\begin{array}{l}\text { Congenital } \\
\text { progressive }\end{array}$ & Severe to profound & Japan & Miyagawa,2013 \\
\hline & & & & Het & Pre-lingual & Severe & Japan & Miyagawa,2013 \\
\hline & & & & Het & Congenital & Severe to profound & Japan & Miyagawa,2013 \\
\hline \multirow[t]{2}{*}{ c.10249_10251delTCC } & p. Ser3417del & 64 & FERM 2 & Het & Congenital & profound & Japan & Miyagawa,2015 \\
\hline & & & & Het & $\begin{array}{l}\text { Post-lingual } \\
\text { progressive }\end{array}$ & $\begin{array}{l}\text { Residual low frequencies } \\
\text { hearing }\end{array}$ & Korea & Chang,2018 \\
\hline
\end{tabular}

Abbreviations: NA not available, Hom homozygous variant, Het compound heterozygous mutation variant

variant (p.Tyr289*) affecting the $\mathrm{N}$-terminal domain. The audiograms of three affected siblings revealed congenital severe to profound sensorineural hearing loss at all frequencies, while their mother showed progressive severe sensorineural hearing loss of a milder form, which suggested the presence of a modifier. To our knowledge, in 
general, autosomal dominant non-syndromic hearing loss (ADNSHL) were associated with post-lingual hearing impairment, whereas ARNSHL were associated with congenital or pre-lingual hearing impairment. However, according to the results of our literature review, there were $8 M Y O 15 A$ variant cases from Japan and Korea with unconventional post-lingual hearing impairment (Table 2). It should be noted that unlike the majority of MYO15A variant cases with a stable auditory phenotype, progressive hearing loss, especially at low frequencies, was observed in both affected individuals with a less severe auditory phenotype in our study based on 3-year auditory follow-ups, which further demonstrated the phenotypic diversity of the $M Y O 15 A$ variant.

Genetic modifiers or environmental factors might contribute to the complex genotype-phenotype correlations of MYO15A variants [9]. In addition, it is noteworthy that in contrast to conventional genetic tests such as linkage analysis, the more cost-effective and highly efficient technology of next-generation sequencing (NGS), which was commonly employed after 2012, saw a dramatic increase in the number of pathogenic variants identified. With the use of NGS, more sporadic cases with milder auditory phenotypes from non-consanguineous families have the opportunity to be involved in genetic studies to identify pathogenic gene variants. Therefore, more MYO15A compound heterozygous variants have been identified from various ethnic groups, without being limited to consanguineous families of the Middle East. This enriches the pool of known genotypes and phenotypes of MYO15A variants. It is also worth noting that there were several cases of progressive hearing loss both in recent reports and in our present study, therefore it is necessary to focus not only on age of onset but also age of auditory testing when performing genotype-phenotype correlation analyses. Gathering sufficient historical data and long-term follow-up related to auditory testing are fundamental to establishing specific genotype-phenotype correlations.

\section{Conclusions}

In summary, we identified 16 novel variants and 12 reported pathogenic MYO15A variants in 15 NSHL patients. Additionally, we described two distinct auditory phenotypes, a severe phenotype and a milder phenotype, in the present study. Our work extends the spectrum of MYO15A pathogenic variants, enriches our knowledge of auditory phenotypes, and deepens our understanding of the MYO15A genotype-phenotype correlation. In the future, additional functional studies including more cases with phenotypes based on accurate assessments of hearing loss phenotypes are necessary to ascertain the MYO15A genotype-phenotype correlation and provide optimal rehabilitation methods for affected individuals through precisely targeted genetic counselling.

\section{Additional files}

Additional file 1: Table S1. List of 127 targeted genes or related regions. (DOCX $15 \mathrm{~kb}$ )

Additional file 2: Figure S1. Pedigrees of the families carried MYO15A variants. (PDF $420 \mathrm{~kb}$ )

Additional file 3: Table S2. Variants of MYO15A detected in this study. (DOCX $25 \mathrm{~kb})$

\section{Abbreviations}

ABR: Auditory brainstem response; ADNSHL: Autosomal dominant nonsyndromic hearing loss; ARNSHL: Autosomal recessive non-syndromic hearing loss; ASSR: Auditory steady state response; BWA: Burrows-Wheeler Aligner; DPOAE: Distortion product otoacoustic emission; GATK: Genome Analysis Toolkit; NGS: Next-generation sequencing; NSHL: Non-syndromic hearing loss; OAE: Otoacoustic emission; PTA: pure-tone audiometry

\section{Acknowledgements}

We thank the families included in the study for their invaluable cooperation and participation in this work.

\section{Funding}

This work was supported by grants from the National Natural Science Foundation of China, Nos. 81830028, 81530032 and the National Key Basic Research Program of China, No. 2014CB943001.

The funders had no role in study design, data collection and analysis, decision to publish, or preparation of the manuscript. The authors have no other funding, financial relationships, or conflicts of interest to disclose.

\section{Availability of data and materials}

The datasets used and/or analysed during the current study are available from the corresponding author upon request.

\section{Authors' contributions}

Conceived and designed the experiments: QW, JZ, JG, HW. Performed the experiments: JZ, JG, HW. Analysed the data: JZ, JG, HW, LY. Contributed reagents/materials/analysis tools: LZ, DW. Wrote the paper: JZ. Critical reading and discussion of manuscript: QW, JG, HZ. All authors have read and approved the final manuscript.

\section{Ethics approval and consent to participate}

The study was approved by the Committee of Medical Ethics of Chinese PLA General Hospital. We obtained a written informed consent from all the participants in this study. Written informed consent was obtained from the next of kin on behalf of the minor/child participants involved in this study.

\section{Consent for publication}

We obtained the written informed consents for publication from all the participants. Written informed consents for publication were obtained from the next of kin on the behalf of the minors/children participants involved in this study.

\section{Competing interests}

The authors declare that they have no competing interests.

\section{Publisher's Note}

Springer Nature remains neutral with regard to jurisdictional claims in published maps and institutional affiliations.

\section{Author details}

${ }^{1}$ Chinese PLA Institute of Otolaryngology, Chinese PLA General Hospital, Medical School of Chinese PLA, 28 Fuxing Road, Beijing 100853, China. 
${ }^{2}$ Department of Otolaryngology of Tianjin Medical University General Hospital, Tianjin 300052, China. ${ }^{3}$ BGI-Shenzhen, Shenzhen 518120, China.

\section{Received: 1 December 2018 Accepted: 20 March 2019 Published online: 05 April 2019}

\section{References}

1. Richard EM, Santos-Cortez RLP, Faridi R, Rehman AU, Lee K, Shahzad M, Acharya A, Khan AA, Imtiaz A, Chakchouk I, et al. Global genetic insight contributed by consanguineous Pakistani families segregating hearing loss. Hum Mutat. 2019:40(1):53-72.

2. Rehman AU, Bird JE, Faridi R, Shahzad M, Shah S, Lee K, Khan SN, Imtiaz A, Ahmed ZM, Riazuddin S, et al. Mutational Spectrum of MYO15A and the molecular mechanisms of DFNB3 human deafness. Hum Mutat. 2016;37(10): 991-1003.

3. Fattahi Z, Shearer AE, Babanejad M, Bazazzadegan N, Almadani SN, Nikzat N, Jalalvand K, Arzhangi S, Esteghamat F, Abtahi R, et al. Screening for MYO15A gene mutations in autosomal recessive nonsyndromic, GJB2 negative Iranian deaf population. Am J Med Genet A. 2012;158a(8):1857-64.

4. Redowicz MJ. Myosins and deafness. J Muscle Res Cell Motil. 1999:20(3): 241-8.

5. Wang A, Liang Y, Fridell RA, Probst FJ, Wilcox ER, Touchman JW, Morton CC, Morell RJ, Noben-Trauth K, Camper SA, et al. Association of unconventional myosin MYO15 mutations with human nonsyndromic deafness DFNB3. Science. 1998;280(5368):1447-51.

6. Wakabayashi Y, Takahashi Y, Kikkawa Y, Okano H, Mishima Y, Ushiki T, Yonekawa $\mathrm{H}$, Kominami R. A novel type of myosin encoded by the mouse deafness gene shaker-2. Biochem Biophys Res Commun. 1998;248(3):655-9.

7. Probst FJ, Fridell RA, Raphael Y, Saunders TL, Wang A, Liang Y, Morell RJ, Touchman JW, Lyons RH, Noben-Trauth $\mathrm{K}$, et al. Correction of deafness in shaker-2 mice by an unconventional myosin in a BAC transgene. Science. 1998;280(5368):1444-7.

8. Liang Y, Wang A, Belyantseva IA, Anderson DW, Probst FJ, Barber TD, Mille W, Touchman JW, Jin L, Sullivan SL, et al. Characterization of the human and mouse unconventional myosin XV genes responsible for hereditary deafness DFNB3 and shaker 2. Genomics. 1999;61(3):243-58.

9. Chang MY, Lee C, Han JH, Kim MY, Park HR, Kim N, Park WY, Oh DY, Choi BY. Expansion of phenotypic spectrum of MYO15A pathogenic variants to include postlingual onset of progressive partial deafness. BMC Med Genet. 2018;19(1):29.

10. Naz S, Imtiaz A, Mujtaba G, Maqsood A, Bashir R, Bukhari I, Khan MR, Ramzan M, Fatima A, Rehman AU, et al. Genetic causes of moderate to severe hearing loss point to modifiers. Clin Gnetics. 2017;91(4):589-98.

11. Wang H, Zhao Y, Yi Y, Gao Y, Liu Q, Wang D, Li Q, Lan L, Li N, Guan J, et al. Targeted high-throughput sequencing identifies pathogenic mutations in KCNQ4 in two large Chinese families with autosomal dominant hearing loss. PLoS One. 2014;9(8):e103133.

12. Sloan-Heggen $C M$, Bierer $A O$, Shearer $A E$, Kolbe DL, Nishimura $C J$, Frees $K L$, Ephraim SS, Shibata SB, Booth KT, Campbell CA, et al. Comprehensive genetic testing in the clinical evaluation of 1119 patients with hearing loss. Hum Genet. 2016;135(4):441-50.

13. Li W, Guo L, Li Y, Wu Q, Li Q, Li H, Dai C. A novel recessive truncating mutation in MY015A causing prelingual sensorineural hearing loss. Int J Pediatr Otorhinolaryngol. 2016;81:92-5.

14. Park JH, Kim NK, Kim AR, Rhee J, Oh SH, Koo JW, Nam JY, Park WY, Choi BY. Exploration of molecular genetic etiology for Korean cochlear implantees with severe to profound hearing loss and its implication. Orphanet J Rare Dis. 2014;9:167.

15. Bademci G, Foster J 2nd, Mahdieh N, Bonyadi M, Duman D, Cengiz FB, Menendez I, Diaz-Horta O, Shirkavand A, Zeinali S, et al. Comprehensive analysis via exome sequencing uncovers genetic etiology in autosomal recessive nonsyndromic deafness in a large multiethnic cohort. Genet Med. 2016;18(4):364-71

16. Diaz-Horta O, Duman D, Foster J 2nd, Sirmaci A, Gonzalez M, Mahdieh N, Fotouhi N, Bonyadi M, Cengiz FB, Menendez I, et al. Whole-exome sequencing efficiently detects rare mutations in autosomal recessive nonsyndromic hearing loss. PLoS One. 2012;7(11):e50628

17. Cengiz FB, Duman D, Sirmaci A, Tokgoz-Yilmaz S, Erbek S, Ozturkmen-Akay $H$, Incesulu A, Edwards YJ, Ozdag H, Liu XZ, et al. Recurrent and private MYO15A mutations are associated with deafness in the Turkish population. Genet Test Mol Biomarkers. 2010;14(4):543-50.
18. Motavaf M, Soveizi M, Maleki M, Mahdieh N. MYO15A splicing mutations in hearing loss: a review literature and report of a novel mutation. Int J Pediatr Otorhinolaryngol. 2017;96:35-8.

19. Gao X, Zhu QY, Song YS, Wang GJ, Yuan YY, Xin F, Huang SS, Kang DY, Han MY, Guan LP, et al. Novel compound heterozygous mutations in the MY015A gene in autosomal recessive hearing loss identified by wholeexome sequencing. J Transl Med. 2013;11:284.

20. Yang T, Wei X, Chai Y, Li L, Wu H. Genetic etiology study of the nonsyndromic deafness in Chinese Hans by targeted next-generation sequencing. Orphanet J Rare Dis. 2013;8:85.

21. Liu WH, Chang PY, Chang SC, Lu JJ, Wu CM. Mutation screening in nonsyndromic hearing loss patients with cochlear implantation by massive parallel sequencing in Taiwan. PLoS One. 2019;14(1):e0211261.

22. Nal N, Ahmed ZM, Erkal E, Alper OM, Luleci G, Dinc O, Waryah AM, Ain Q, Tasneem S, Husnain T, et al. Mutational spectrum of MYO15A: the large Nterminal extension of myosin XVA is required for hearing. Hum Mutat. 2007; 28(10):1014-9.

23. Ma D, Shen S, Gao H, Guo H, Lin Y, Hu Y, Zhang R, Wang S. A novel nonsense mutation in MYO15A is associated with non-syndromic hearing loss: a case report. BMC Med Genet. 2018;19(1):133.

24. Woo HM, Park HJ, Baek JI, Park MH, Kim UK, Sagong B, Koo SK. Wholeexome sequencing identifies MYO15A mutations as a cause of autosomal recessive nonsyndromic hearing loss in Korean families. BMC Med Genet. 2013;14:72.

25. Baux D, Vache C, Blanchet C, Willems M, Baudoin C, Moclyn M, Faugere V, Touraine R, Isidor B, Dupin-Deguine D, et al. Combined genetic approaches yield a $48 \%$ diagnostic rate in a large cohort of French hearing-impaired patients. Sci Rep. 2017;7(1):16783.

26. Salime S, Charif M, Bousfiha A, Elrharchi S, Bakhchane A, Charoute H, Kabine M, Snoussi K, Lenaers G, Barakat A. Homozygous mutations in PJVK and MYO15A genes associated with non-syndromic hearing loss in Moroccan families. Int J Pediatr Otorhinolaryngol. 2017;101:25-9.

27. Plevova P, Paprskarova M, Tvrda P, Turska P, Slavkovsky R, Mrazkova E. STRC Deletion is a Frequent Cause of Slight to Moderate Congenital Hearing Impairment in the Czech Republic. Otol Neurotol. 2017;38(10):e393-400.

28. Jung J, Lee JS, Cho KJ, Yu S, Yoon JH, Yung Gee H, Choi JY. Genetic predisposition to sporadic congenital hearing loss in a pediatric population. Sci Rep. 2017:7:45973.

29. Zazo Seco C, Wesdorp M, Feenstra I, Pfundt R, Hehir-Kwa JY, Lelieveld SH, Castelein S, Gilissen C, de Wijs IJ, Admiraal RJ, et al. The diagnostic yield of whole-exome sequencing targeting a gene panel for hearing impairment in the Netherlands. Eur J Hum Genet. 2017;25(3):308-14.

30. Manzoli GN, Bademci G, Acosta AX, Felix TM, Cengiz FB, Foster J 2nd, Da Silva DS, Menendez I, Sanchez-Pena I, Tekin D, et al. Targeted resequencing of deafness genes reveals a founder MYO15A variant in northeastern Brazil. Ann Hum Genet. 2016;80(6):327-31.

31. Palombo F, Al-Wardy N, Ruscone GA, Oppo M, Kindi MN, Angius A, Al Lamk K, Girotto G, Giangregorio T, Benelli M, et al. A novel founder MY015A frameshift duplication is the major cause of genetic hearing loss in Oman. J Hum Genet. 2017;62(2):259-64.

32. Reiisi S, Tabatabaiefar MA, Sanati MH, Chaleshtori MH. Screening of DFNB3 in Iranian families with autosomal recessive non-syndromic hearing loss reveals a novel pathogenic mutation in the MyTh4 domain of the MYO15A gene in a linked family. Iran J Basic Med Sci. 2016;19(7):772-8.

33. Yan D, Tekin D, Bademci G, Foster J 2nd, Cengiz FB, Kannan-Sundhari A Guo S, Mittal R, Zou B, Grati M, et al. Spectrum of DNA variants for nonsyndromic deafness in a large cohort from multiple continents. Hum Genet. 2016;135(8):953-61.

34. Sommen M, Schrauwen I, Vandeweyer G, Boeckx N, Corneveaux JJ, van den Ende J, Boudewyns A, De Leenheer E, Janssens S, Claes K, et al. DNA diagnostics of hereditary hearing loss: a targeted resequencing approach combined with a mutation classification system. Hum Mutat. 2016;37(8): $812-9$.

35. Chen JR, Tang ZH, Zheng J, Shi HS, Ding J, Qian XD, Zhang C, Chen JL, Wang CC, Li L, et al. Effects of genetic correction on the differentiation of hair cell-like cells from iPSCs with MYO15A mutation. Cell Death Differ. 2016; 23(8):1347-57.

36. Moteki H, Azaiez H, Booth KT, Shearer AE, Sloan CM, Kolbe DL, Nishio S, Hattori M, Usami S, Smith RJ. Comprehensive genetic testing with ethnicspecific filtering by allele frequency in a Japanese hearing-loss population. Clin Genet. 2016;89(4):466-72. 
37. Sloan-Heggen CM, Babanejad M, Beheshtian M, Simpson AC, Booth KT, Ardalani F, Frees KL, Mohseni M, Mozafari R, Mehrjoo Z, et al. Characterising the spectrum of autosomal recessive hereditary hearing loss in Iran. J Med Genet. 2015;52(12):823-9.

38. Atik T, Onay H, Aykut A, Bademci G, Kirazli T, Tekin M, Ozkinay F. Comprehensive analysis of deafness genes in families with autosomal recessive nonsyndromic hearing loss. PLoS One. 2015;10(11):e0142154.

39. Svidnicki MC, Silva-Costa SM, Ramos PZ, dos Santos NZ, Martins FT, Castilho AM Sartorato EL. Screening of genetic alterations related to non-syndromic hearing loss using MassARRAY iPLEX(R) technology. BMC Med Genet. 2015;16:85.

40. Xia H, Huang X, Guo Y, Hu P, He G, Deng X, Xu H, Yang Z, Deng H. Identification of a novel MYO15A mutation in a Chinese family with autosomal recessive nonsyndromic hearing loss. PLoS One. 2015;10(8):e0136306.

41. Gu X, Guo L, Ji H, Sun S, Chai R, Wang L, Li H. Genetic testing for sporadic hearing loss using targeted massively parallel sequencing identifies 10 novel mutations. Clin Genet. 2015;87(6):588-93.

42. Chen $Y$, Wang $Z$, Wang $Z$, Chen $D$, Chai $Y$, Pang $X$, Sun L, Wang $X$, Yang $T$, Wu H. Targeted next-generation sequencing in Uyghur families with nonsyndromic sensorineural hearing loss. PLoS One. 2015;10(5):e0127879.

43. Chang MY, Kim AR, Kim NK, Lee C, Lee KY, Jeon WS, Koo JW, Oh SH, Park WY, Kim D, et al. Identification and clinical implications of novel MYO15A mutations in a non-consanguineous Korean family by targeted exome sequencing. Mol Cells. 2015;38(9):781-8.

44. Ammar-Khodja F, Bonnet C, Dahmani M, Ouhab S, Lefevre GM, Ibrahim H, Hardelin JP, Weil D, Louha M, Petit C. Diversity of the causal genes in hearing impaired Algerian individuals identified by whole exome sequencing. Mol Genet Genom Med. 2015;3(3):189-96.

45. Miyagawa M, Nishio SY, Hattori M, Moteki H, Kobayashi Y, Sato H, Watanabe T, Naito Y, Oshikawa C, Usami S. Mutations in the MYO15A gene are a significant cause of nonsyndromic hearing loss: massively parallel DNA sequencing-based analysis. Ann Otol Rhinol Laryngol. 2015;124(Suppl 1):158s-68s.

46. Nishio SY, Usami S. Deafness gene variations in a 1120 nonsyndromic hearing loss cohort: molecular epidemiology and deafness mutation spectrum of patients in Japan. Ann Otol Rhinol Laryngol. 2015;124(Suppl 1):49s-60s.

47. Shafique S, Siddiqi S, Schraders M, Oostrik J, Ayub H, Bilal A, Ajmal M, Seco CZ, Strom TM, Mansoor A, et al. Genetic spectrum of autosomal recessive non-syndromic hearing loss in Pakistani families. PLoS One. 2014;9(6): e100146.

48. Riahi Z, Bonnet C, Zainine R, Louha M, Bouyacoub Y, Laroussi N, Chargui M, Kefi $R$, Jonard L, Dorboz I, et al. Whole exome sequencing identifies new causative mutations in Tunisian families with non-syndromic deafness. PLoS One. 2014;9(6):e99797.

49. Vozzi D, Morgan A, Vuckovic D, D'Eustacchio A, Abdulhadi K, Rubinato E, Badii R, Gasparini P, Girotto G. Hereditary hearing loss: a 96 gene targeted sequencing protocol reveals novel alleles in a series of Italian and Qatari patients. Gene. 2014;542(2):209-16.

50. Brownstein Z, Abu-Rayyan A, Karfunkel-Doron D, Sirigu S, Davidov B, Shohat M, Frydman M, Houdusse A, Kanaan M, Avraham KB. Novel myosin mutations for hereditary hearing loss revealed by targeted genomic capture and massively parallel sequencing. Eur J Hum Genet. 2014;22(6):768-75.

51. Vona B, Muller T, Nanda I, Neuner C, Hofrichter MA, Schroder J, Bartsch O, Lassig A, Keilmann A, Schraven S, et al. Targeted next-generation sequencing of deafness genes in hearing-impaired individuals uncovers informative mutations. Genet Med. 2014;16(12):945-53.

52. Miyagawa M, Nishio SY, Ikeda T, Fukushima K, Usami S. Massively parallel DNA sequencing successfully identifies new causative mutations in deafness genes in patients with cochlear implantation and EAS. PLoS One. 2013;8(10):e75793.

53. Miyagawa M, Naito T, Nishio SY, Kamatani N, Usami S. Targeted exon sequencing successfully discovers rare causative genes and clarifies the molecular epidemiology of Japanese deafness patients. PLoS One. 2013;8(8): e71381.

54. Bashir R, Fatima A, Naz S. Prioritized sequencing of the second exon of MY015A reveals a new mutation segregating in a Pakistani family with moderate to severe hearing loss. Eur J Med Genet. 2012;55(2):99-102.

55. Schrauwen I, Sommen M, Corneveaux JJ, Reiman RA, Hackett NJ, Claes C, Claes K, Bitner-Glindzicz M, Coucke P, Van Camp G, et al. A sensitive and specific diagnostic test for hearing loss using a microdroplet PCR-based approach and next generation sequencing. Am J Med Genet A. 2013; 161a(1):145-52.

56. Brownstein Z, Friedman LM, Shahin H, Oron-Karni V, Kol N, Abu Rayyan A, Parzefall T, Lev D, Shalev S, Frydman M, et al. Targeted genomic capture and massively parallel sequencing to identify genes for hereditary hearing loss in middle eastern families. Genome Biol. 2011;12(9):R89.

57. Duman D, Sirmaci A, Cengiz FB, Ozdag H, Tekin M. Screening of 38 genes identifies mutations in $62 \%$ of families with nonsyndromic deafness in Turkey. Genet Test Mol Biomarkers. 2011;15(1-2):29-33.

58. Shahin H, Walsh T, Rayyan AA, Lee MK, Higgins J, Dickel D, Lewis K, Thompson J, Baker C, Nord AS, et al. Five novel loci for inherited hearing loss mapped by SNP-based homozygosity profiles in Palestinian families. Eur J Hum Genet. 2010;18(4):407-13.

59. Belguith H, Aifa-Hmani M, Dhouib H, Said MB, Mosrati MA, Lahmar I, Moalla J. Charfeddine I, Driss N, Arab SB, et al. Screening of the DFNB3 locus: identification of three novel mutations of MYO15A associated with hearing loss and further suggestion for two distinctive genes on this locus. Genet Test Mol Biomarkers. 2009;13(1):147-51.

60. Shearer AE, Hildebrand MS, Webster JA, Kahrizi K, Meyer NC, Jalalvand K, Arzhanginy S, Kimberling WJ, Stephan D, Bahlo M, et al. Mutations in the first MyTH4 domain of MYO15A are a common cause of DFNB3 hearing loss. Laryngoscope. 2009;119(4):727-33.

61. Lezirovitz K, Pardono E, de Mello Auricchio MT, de Carvalho ESFL, Lopes JJ, Abreu-Silva RS, Romanos J, Batissoco AC, Mingroni-Netto RC. Unexpected genetic heterogeneity in a large consanguineous Brazilian pedigree presenting deafness. Eur J Hum Genet. 2008;16(1):89-96.

62. Kalay E, Uzumcu A, Krieger E, Caylan R, Uyguner O, Ulubil-Emiroglu M, Erdol H, Kayserili H, Hafiz G, Baserer N, et al. MYO15A (DFNB3) mutations in Turkish hearing loss families and functional modeling of a novel motor domain mutation. Am J Med Genet A. 2007:143a(20):2382-9.

63. Friedman TB, Hinnant JT, Ghosh M, Boger ET, Riazuddin S, Lupski JR, Potocki L, Wilcox ER. DFNB3, spectrum of MYO15A recessive mutant alleles and an emerging genotype-phenotype correlation. Adv Otorhinolaryngol. 2002;61:124-30.

64. Liburd N, Ghosh M, Riazuddin S, Naz S, Khan S, Ahmed Z, Riazuddin S, Liang $Y$, Menon PS, Smith T, et al. Novel mutations of MYO15A associated with profound deafness in consanguineous families and moderately severe hearing loss in a patient with Smith-Magenis syndrome. Hum Genet. 2001; 109(5):535-41.

65. Mehregan $H$, Mohseni M, Jalalvand K, Arzhangi S, Nikzat N, Banihashemi S, Kahrizi K, Najmabadi H. Novel mutations in MYTH4-FERM domains of myosin 15 are associated with autosomal recessive nonsyndromic hearing loss. Int J Pediatr Otorhinolaryngol. 2018;117:115-26.

66. Zhang F, Xu L, Xiao Y, Li J, Bai X, Wang H. Three MYO15A mutations identified in one Chinese family with autosomal recessive nonsyndromic hearing loss. Neural Plast. 2018;2018:5898025.

67. Chen Y, Lu Y, Kuyaxi P, Cheng J, Zhao J, Zhao Q, Musha P, Zhang H, Yuan $H$. Identification of pathogenic genes of nonsyndromic hearing loss in Uyghur families using massively parallel DNA sequencing technique. Dis Markers. 2018;2018:5298057.

68. Cabanillas R, Dineiro M, Cifuentes GA, Castillo D, Pruneda PC, Alvarez R, Sanchez-Duran N, Capin R, Plasencia A, Viejo-Diaz M, et al. Comprehensive genomic diagnosis of non-syndromic and syndromic hereditary hearing loss in Spanish patients. BMC Med Genet. 2018;11(1):58.

69. Danial-Farran N, Brownstein Z, Gulsuner S, Tammer L, Khayat M, Aleme O, Chervinsky E, Zoubi OA, Walsh T, Ast G, et al. Genetics of hearing loss in the Arab population of northern Israel. Eur J Hum Genet. 2018;26(12):1840-7.

70. Friedman TB, Liang Y, Weber JL, Hinnant JT, Barber TD, Winata S, Arhya IN Asher JH Jr. A gene for congenital, recessive deafness DFNB3 maps to the pericentromeric region of chromosome 17. Nat Genet. 1995;9(1):86-91.

71. Liang Y, Wang A, Probst FJ, Arhya IN, Barber TD, Chen KS, Deshmukh D, Dolan DF, Hinnant JT, Carter LE, et al. Genetic mapping refines DFNB3 to 17p11.2, suggests multiple alleles of DFNB3, and supports homology to the mouse model shaker-2. Am J Hum Genet. 1998;62(4):904-15.

72. Belyantseva IA, Boger ET, Naz S, Frolenkov GI, Sellers JR, Ahmed ZM, Griffith AJ, Friedman TB. Myosin-XVa is required for tip localization of whirlin and differential elongation of hair-cell stereocilia. Nat Cell Biol. 2005;7(2):148-56.

73. Anderson DW, Probst FJ, Belyantseva IA, Fridell RA, Beyer L, Martin DM, Wu D, Kachar B, Friedman TB, Raphael Y, et al. The motor and tail regions of myosin $\mathrm{XV}$ are critical for normal structure and function of auditory and vestibular hair cells. Hum Mol Genet. 2000;9(12):1729-38.

74. Fang Q, Indzhykulian AA, Mustapha M, Riordan GP, Dolan DF, Friedman TB, Belyantseva IA, Frolenkov GI, Camper SA, Bird JE. The 133-kDa N-terminal domain enables myosin 15 to maintain mechanotransducing stereocilia and is essential for hearing. Elife. 2015;4:e08627. 